\title{
Front Matter: Volume 9837
}

, "Front Matter: Volume 9837," Proc. SPIE 9837, Unmanned Systems Technology XVIII, 983701 (23 June 2016); doi: 10.1117/12.2245780

SPIE. Event: SPIE Defense + Security, 2016, Baltimore, MD, United States 


\title{
PROCEEDINGS OF SPIE
}

\section{Unmanned Systems Technology XVIII}

\author{
Robert E. Karlsen \\ Douglas W. Gage \\ Charles M. Shoemaker \\ Grant R. Gerhart \\ Editors
}

20-21 April 2016

Baltimore, Maryland, United States

Sponsored and Published by

SPIE 
The papers in this volume were part of the technical conference cited on the cover and title page. Papers were selected and subject to review by the editors and conference program committee. Some conference presentations may not be available for publication. Additional papers and presentation recordings may be available online in the SPIE Digital Library at SPIEDigitallibrary.org.

The papers reflect the work and thoughts of the authors and are published herein as submitted. The publisher is not responsible for the validity of the information or for any outcomes resulting from reliance thereon.

Please use the following format to cite material from these proceedings:

Author(s), "Title of Paper," in Unmanned Systems Technology XVIII, edited by Robert E. Karlsen, Douglas W. Gage, Charles M. Shoemaker, Grant R. Gerhart, Proceedings of SPIE Vol. 9837 (SPIE, Bellingham, WA, 2016) Six-digit Article CID Number.

ISSN: 0277-786X

ISSN: 1996-756X (electronic)

ISBN: 9781510600782

Published by

SPIE

P.O. Box 10, Bellingham, Washington 98227-0010 USA

Telephone +1 3606763290 (Pacific Time) · Fax +1 3606471445

SPIE.org

Copyright (C) 2016, Society of Photo-Optical Instrumentation Engineers.

Copying of material in this book for internal or personal use, or for the internal or personal use of specific clients, beyond the fair use provisions granted by the U.S. Copyright Law is authorized by SPIE subject to payment of copying fees. The Transactional Reporting Service base fee for this volume is $\$ 18.00$ per article (or portion thereof), which should be paid directly to the Copyright Clearance Center (CCC), 222 Rosewood Drive, Danvers, MA 01923. Payment may also be made electronically through CCC Online at copyright.com. Other copying for republication, resale, advertising or promotion, or any form of systematic or multiple reproduction of any material in this book is prohibited except with permission in writing from the publisher. The CCC fee code is 0277-786X/16/\$18.00.

Printed in the United States of America.

Publication of record for individual papers is online in the SPIE Digital Library.

\section{SPIE. DIGITAL}

SPIEDigitalLibrary.org

Paper Numbering: Proceedings of SPIE follow an e-First publication model. A unique citation identifier (CID) number is assigned to each article at the time of publication. Utilization of CIDs allows articles to be fully citable as soon as they are published online, and connects the same identifier to all online and print versions of the publication. SPIE uses a six-digit CID article numbering system structured as follows:

- The first four digits correspond to the SPIE volume number.

- The last two digits indicate publication order within the volume using a Base 36 numbering

system employing both numerals and letters. These two-number sets start with 00, 01, 02, 03, 04, 05, 06, 07, 08, 09, 0A, OB ... 0Z, followed by 10-1Z, 20-2Z, etc. The CID Number appears on each page of the manuscript. 


\title{
Contents
}

\author{
vii Authors \\ ix Conference Committee \\ xi Introduction
}

NAVIGATION FOR UNMANNED VEHICLES: JOINT SESSION WITH CONFERENCES 9849 AND 9837

983702 Non-GPS full position and angular orientation onboard sensors for moving and stationary plafforms [9837-1]

983703 Optimal vehicle planning and the search tour problem [9837-2]

983704 Incremental learning in trust-based vehicle control [9837-3]

983705 Mobility versus terrain: a game theoretic approach [9837-4]

983706 Ant-based distributed protocol for coordination of a swarm of robots in demining mission [9837-5]

SPECIAL TOPICS

983707 A new application for analyzing driving behaviour and environment characterization in transportation systems based on a fuzzy logic approach [9837-6]

983708 Probabilistic monitoring in intrusion detection module for energy efficiency in mobile ad hoc networks [9837-7]

983709 Human guidance of mobile robots in complex 3D environments using smart glasses [9837-8]

9837 OA Planning energy-efficient bipedal locomotion on patterned terrain [9837-10]

9837 OB High power free space optical link for rapid energy and data transmission [9837-1 1]

PERCEPTION

9837 OD LWIR passive perception system for stealthy unmanned ground vehicle night operations [9837-13]

9837 OE Obstacles and foliage discrimination using lidar [9837-14] 
9837 OF Landmark-based robust navigation for tactical UGV control in GPS-denied

communication-degraded environments [9837-15]

\section{ROBOTICS CTA I}

$9837 \mathrm{OH} \quad$ Towards bipedal behavior on a quadrupedal platform using optimal control [9837-17]

9837 Ol Gait development on Minitaur, a direct drive quadrupedal robot [9837-18]

9837 0J Simulation tools for robotics research and assessment [9837-19]

9837 OK Interactive multi-objective path planning through a palette-based user interface [9837-20]

$9837 \mathrm{OL} \quad$ Clustering social cues to determine social signals: developing learning algorithms using the "n-most likely states" approach [9837-21]

\section{ROBOTICS CTA II}

$9837 \mathrm{OM}$ A multimodal interface for real-time soldier-robot teaming [9837-22]

9837 ON Technological evaluation of gesture and speech interfaces for enabling dismounted soldier-robot dialogue [9837-23]

$983700 \quad$ Learning object models from few examples [9837-24]

9837 OP Incorporating polarization in stereo vision-based 3D perception of non-Lambertian scenes [9837-25]

$9837 \mathrm{OQ} \quad$ Improving semantic scene understanding using prior information [9837-26]

9837 OR Video-based convolutional neural networks for activity recognition from robot-centric videos [9837-27]

\section{POSTER SESSION}

9837 OS An energy-efficient architecture for internet of things systems [9837-28]

9837 OT A fast and scalable content transfer protocol (FSCTP) for VANET based architecture [9837-30]

9837 OU Implementation of a large solar collector for electric charge generation [9837-31]

9837 OV Comparison of gradient methods for gain tuning of a PD controller applied on a quadrotor system [9837-32] 
9837 OW LiPo battery energy studies for improved flight performance of unmanned aerial systems [9837-33]

9837 0X Implementing a dynamometer system on electric motors for unmanned systems [9837-34] 
Proc. of SPIE Vol. $9837983701-6$

Downloaded From: https://www.spiedigitallibrary.org/conference-proceedings-of-spie on 26 Apr 2023 Terms of Use: https://www.spiedigitallibrary.org/terms-of-use 
Proc. of SPIE Vol. $9837983701-8$

Downloaded From: https://www.spiedigitallibrary.org/conference-proceedings-of-spie on 26 Apr 2023 Terms of Use: https://www.spiedigitallibrary.org/terms-of-use 


\section{Conference Committee}

Symposium Chair

David A. Logan, BAE Systems (United States)

Symposium Co-chair

Donald A. Reago Jr., U.S. Army Night Vision \& Electronic Sensors

Directorate (United States)

\section{Conference Chairs}

Robert E. Karlsen, U.S. Army Tank Automotive Research, Development and Engineering Center (United States)

Douglas W. Gage, XPM Technologies (United States)

Charles M. Shoemaker, U.S. Army Communications-Electronics Research Development and Engineering Command (United States)

Grant R. Gerhart, U.S. Army Tank-Automotive Research,

Development, and Engineering Center-Retired (United States)

Conference Program Committee

Jonathan A. Bornstein, U.S. Army Research Laboratory (United States) Jared Giesbrecht, Defence Research and Development Canada, Suffield (Canada)

Frank L. Lewis, The University of Texas at Arlington (United States)

Larry H. Matthies, Jet Propulsion Laboratory (United States)

Camille S. Monnier, Charles River Analytics, Inc. (United States)

Paul L. Muench, U.S. Army Tank Automotive Research, Development and Engineering Center (United States)

Hoa G. Nguyen, Space and Naval Warfare Systems Center Pacific (United States)

James L. Overholt, Air Force Research Laboratory (United States)

Gary Witus, Turing Associates, Inc. (United States)

Brian M. Yamauchi, iRobot Corporation (United States)

\section{Session Chairs}

1 Self-Organizing, Collaborative Unmanned Robotics Teams: Joint Session with conferences 9837 and 9849

Raja Suresh, General Dynamics Mission Systems (United States)

Robert E. Karlsen, U.S. Army Tank Automotive Research,

Development and Engineering Center (United States) 
2 Navigation for Unmanned Vehicles: Joint Session with conferences 9849 and 9837

Robert E. Karlsen, U.S. Army Tank Automotive Research, Development and Engineering Center (United States)

Raja Suresh, General Dynamics Mission Systems (United States)

3 Special Topics

Douglas W. Gage, XPM Technologies (United States)

Charles M. Shoemaker, U.S. Army Communications-Electronics Research Development and Engineering Command (United States)

4 Perception

Hoa G. Nguyen, Space and Naval Warfare Systems Center Pacific (United States)

Camille S. Monnier, Charles River Analytics, Inc. (United States)

5 Robotics CTA I

Dilip G. Patel, General Dynamics Land Systems (United States)

Jonathan A. Bornstein, U.S. Army Research Laboratory (United States)

6 Robotics CTA II

Dilip G. Patel, General Dynamics Land Systems (United States)

Jonathan A. Bornstein, U.S. Army Research Laboratory (United States) 


\section{Introduction}

The Unmanned Systems Technology XVIII conference consisted of six official sessions (and two unofficial joint sessions) that spanned a full two days and covered a variety of areas within robotics. The conference list of papers shows a wide breadth of applications for unmanned systems, primarily in the defense arena, which are predicted to increase in future years. This year's conference also shows that, while there is still interest in the standard unmanned technologies, there is also great interest in other forms of robotics, such as micro air vehicles, which have become very ubiquitous in terms of commercial availability and capability.

This year the conference kicked off with a pair of (unofficial) joint sessions with Conference 9836, Micro- and Nanotechnology Sensors, Systems, and Applications VIII, consisting of work performed under the Army Research Laboratory's (ARL) Micro-Autonomous Systems and Technology (MAST) Collaborative Technology Alliance (CTA). The first session focused on vision-based techniques for navigation of micro air vehicles, including the sensing to support perching and grasping behaviors and attempts to achieve high speed operation. The second session looked at the important issue of combining human feedback with the control algorithms of autonomous vehicles, including research involving trust in autonomy and the use of eye-tracking and EEG data.

Wednesday afternoon began with a pair of joint sessions with Conference 9849, Open Architecture/Open Business Model Net-Centric Systems and Defense Transformation 2016. The first session was on Self-organizing Collaborative Unmanned ISR Teams, where we heard about efforts in creating open architectures for air and underwater vehicles. The second session was Navigation for Unmanned Vehicles and included papers about measuring the angular orientation of a projectile using a polarized RF source, optimal search patterns for underwater vehicles, trust-based control of convoy vehicles, a game theory approach to mobility, and ant-based coordination.

The poster session took place on Wednesday night and had an energy theme, with papers on energy efficient architectures, solar collector for energy harvesting, and battery energy management, as well papers on a fast data transfer protocol, and PD controllers and electric motors for quadrotors. The session was well attended, and there were many pockets of discussion around the posters.

Thursday morning commenced with the special topics session that resulted in the usual potpourri of papers, including an on-board system for recognizing poor

driving behavior, energy consumption minimization for network intrusion 
detection, human-robot interaction with smart glasses, energy-efficient bipedal locomotion, and a high-power optical link for energy transfer.

The Thursday late morning session was on perception and involved a mix of techniques, including stereo range sensing using LWIR, foliage discrimination using LIDAR, and landmark detection for bio-inspired GPS-denied navigation.

The conference concluded with the afternoon sessions on Thursday, which were devoted to ARL's Robotics CTA, where papers were presented on a variety of subjects, including bipedal walking and gait control for a quadruped, a discussion of simulation environments for robotics, an intuitive interface for path planning, and on detecting social cues in regards to human robot interactions. Additional areas included gesture and speech recognition, vision-based learning for semantic labeling, polarization detection to help with specular reflections in stereo imaging, and deep learning for activity recognition.

This year's conference once again covered a variety of unmanned systems technologies and demonstrated why robotics is such an interesting and exciting area to work in. We want to thank all those that helped make the conference a success this year, and we hope that you enjoy these proceedings and are able to attend and participate in the conference next year in Pasadena, California.

\section{Robert E. Karlsen Douglas W. Gage Charles M. Shoemaker Grant R. Gerhart}

